\title{
PEMBERDAYAAN BADAN USAHA MILIK DESA PANCA SARI AMERTA, DESA SINGAPADU KALER
}

\author{
Putu Adi Suprapto, ${ }^{1}$ Kadek Cahya Dewi, ${ }^{2}$ Ni Made Wirasyanti Dwi Pratiwi ${ }^{3}$ dan \\ Ni Luh Ayu Kartika Yuniastari Sarja ${ }^{4}$ \\ 1,3 Jurusan Akuntansi, Politeknik Negeri Bali \\ ${ }^{2}$ Jurusan Administrasi Niaga, Politeknik Negeri Bali \\ ${ }^{4}$ Jurusan Pariwisata, Politeknik Negeri Bali \\ E-mail : putuadisuprapto@gmail.com
}

\begin{abstract}
ABSTRAK. Badan Usaha Milik Desa Sari Panca Amerta merupakan badan usaha yang dimiliki oleh Desa Singapadu Kaler. Jenis usaha yang dikembangkan di BUMDesa Sari Panca Amerta adalah banking, brokering, serving dan holding. Untuk usaha holding ini bekerja sama dengan kelompok usaha All Terrain Vehicle di lingkungan Desa Singapadu Kaler. Saat ini terdapat beberapa kebutuhan kelompok usaha All Terrain Vehicle seperti air mineral yang diberikan dalam setiap paket penyewaan. Hal ini menjadi prospek pemasaran usaha pengelolaan air minum badan usaha milik desa. Pada saat ini, terdapat beberapa kendala pada badan usaha milik desa seperti keterbatasan alat packaging, labeling kemasan produk, kurangnya manajemen keuangan terkomputerisasi serta keterbatasan dalam hal pemasaran. Berdasarkan permasalahan yang dihadapi, maka akan dilakukan kegiatan bertahap mulai manajemen keuangan sampai pemasaran. Kegiatan dimulai dengan sosialisasi, pemberian peralatan sebagai alat bantu packaging, pemberian bantuan kemasan dan label kemasan, pelatihan manajemen keuangan, serta pembuatan sosial media. Indikator capaian adalah peningkatan pendapatan mitra hingga $50 \%, 50 \%$ produk berisi label kemasan, kemasan produk menjadi lebih menarik dan informatif, mitra mempunyai sosial media sebagai media pemasaran, 1 orang anggota usaha dapat menggunakan aplikasi MyOB dan sistem penjualan. Berdasarkan hasil evaluasi, untuk kegiatan pengemasan, pemasaran dan manajemen keuangan tercapai. Sedangkan untuk target peningkatan pendapatan mitra sebanyak 50\% tidak tercapai dikarenakan adanya pandemi COVID-19 yang berdampak pada ditutupnya objek wisata termasuk All Terrain Vehicle sehingga berkurangnya pesanan air mineral.
\end{abstract}

Kata kunci: badan usaha milik desa; all terrain vehicle; air mineral

\begin{abstract}
Sari Panca Amerta Village Owned Enterprise is a business entity owned by Singapadu Kaler Village. The types of businesses developed at BUMDesa Sari Panca Amerta are banking, brokering, serving and holding. For this holding business, it collaborates with the All Terrain Vehicle business group in the village of Singapadu Kaler. Currently there are several needs for the All Terrain Vehicle business group, such as mineral water provided in each rental package. This is a marketing prospect for the drinking water management business of village-owned enterprises. At this time, there are several obstacles to village-owned enterprises such as limited packaging tools, product packaging labeling, lack of computerized financial management and limitations in terms of marketing. Based on the problems faced, there will be gradual activities from financial management to marketing. The activity began with socialization, providing equipment as a packaging tool, providing packaging and packaging label assistance, financial management training, and creating social media. The achievement indicator is an increase in partner income by up to $50 \%, 50 \%$ of products contain packaging labels, product packaging becomes more attractive and informative, partners have social media as a marketing medium, 1 business member can use the $M y O B$ application and the sales system. Based on the evaluation results, the activities for packaging, marketing and financial management were achieved. Meanwhile, the target of increasing partner income by $50 \%$ was not achieved due to the COVID-19 pandemic which resulted in the closure of tourist attractions including the All Terrain Vehicle, thereby reducing mineral water orders.
\end{abstract}

Keywords: village-owned enterprises; all terrain vehicle; mineral water

\section{PENDAHULUAN}

Badan usaha milik desa merupakan usaha yang diselenggarakan oleh Pemerintahan Desa dengan berlandaskan pada semangat kekeluargaan dan gotong royong. BadanUsaha Milik Desa(BUMDesa) secara yuridis badan usaha milik desa terlegitimasi pada Undang-Undang Republik Indonesia Nomor 6 Tahun 2014 tentang Desa. Desa Singapadu Kaler adalah salah satu desa di Kecamatan Sukawati, Kabupaten Gianyar yang mendirikan BUMDesa tahun 2017 untuk mengoptimalkan kegiatan-kegiatan kepariwisataan yang ada di Desa Wisata Singapadu
Kaler.Adapun nama dari BUMDesa Singapadu Kaler adalah Sari Panca Amerta yang merupakan mitra dalam kegiatan ini. Lokasi mitra berada pada Desa Singapadu Kaler, Kecamatan Sukawati, Kabupaten Gianyar. Jarak lokasi mitra (Desa Singapadu Kaler) dengan pengusul kira-kira 37,4 km. BumDesa Sari Panca Amerta saat ini memiliki tiga orang karyawan. Jenis usaha yang dikembangkan di BUMDesa Sari Panca Amerta adalah banking, brokering, serving dan holding. Usaha bangking ini berupa Koperasi Simpan Pinjam Desa Singapadu Kaler. Usaha brokering berupa jasa pelayanan Pembayaran iuran listrik online, jasa pelayanan pembayaran iuran 
telepon online, jasa pelayanan pembayaran pdam online, jasa pelayanan pembayaran bpjs online, jasa samsat. Usaha Serving berupa warung desa, pengelolaan air minum dan pengelolaan sampah (Suprapto, dkk, 2019). Usaha Holding yang sudah terbentuk adalah kerjasama BUMDesa dengan kelompok usaha ATV di lingkungan Desa Singapadu Kaler. Dengan adanya kerjasama antara kelompok usaha ATV dan BumDesa membentuk paguyuban ATV yang berada dibawah naungan BumDesa. Adanya kebutuhan air mineral dari usaha ATV menjadi prospek pemasaran usaha pengelolaan air minum BumDesa. Munculnya permintaan dan kerjasama produk air mineral merupakan pangsa pasar baru untuk BumDesa.

Meskipun usaha pengelolaan air minum baru dimulai yaitu Januari 2020, I Wayan Karcana sebagai ketua BumDesa Sari Panca Amerta melihat peluang ini sebagai peluang usaha untuk meningkatkan penjualan. Saat ini BumDesa telah memiliki alat untuk penyulingan air dan alat kangen water. Jumlah produk air mineral yang dihasilkan dalam satu kali produksi adalah sebanyak kurang lebih 800 buah. Perencanaan produksi dalam satu hari adalah 1000 buah dengan waktu produksi sekitar 2-3 jam. Produk yang dihasilkan oleh usaha pengelolaan air minum BumDesa Sari Panca Amerta adalah air mineral kemasan $300 \mathrm{ml}$.

Dalam hal manajemen keuangan, mitra hanya melakukan pencatatan manual pengeluaran dan pemasukan serta stok dalam buku kas dan buku stok. Contoh pencatatan stok mitra dapat dilihat pada Gambar 1.

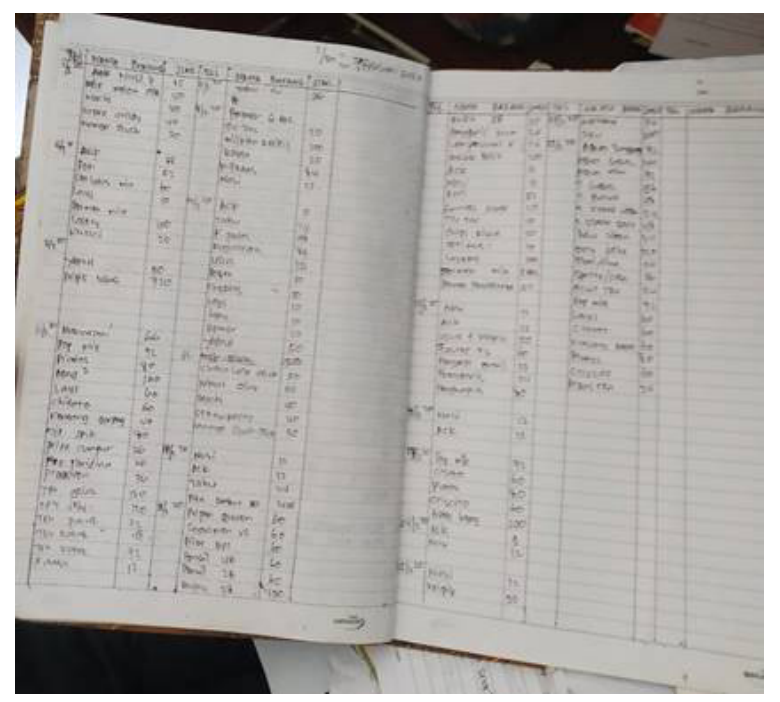

Gambar 1 Pencatatan stok mitra

Pemasaran dan penjualan air mineral adalah usaha ATV dan masyarakat Desa Singapadu Kaler. Kemasan produk air mineral tidak dilengkapi dengan labeling sehingga wisatawan yang mendapatkan air mineral dari menyewa ATV tidak mengetahui lokasi pembuatan air mineral ini. Kendala dalam hal packaging adalah belum adanya packaging dari produk botol air mineral. Selain itu dalam hal pemasaran, belum adanya plang nama usaha untuk memudahkan pemasaran usaha serta label kemasan produk.

BUMDesa lahir sebagai suatu pendekatan baru dalam usaha peningkatan ekonomi desa berdasarkan kebutuhan dan potensi desa (Zulkarnaen, 2016);(Mulyani, dkk, 2018). BUMDesa merupakan usaha pemerintah dalam pengembangan basis ekonomi pedesaan yang ditujukan untuk kesejahteraan masyarakat desa (Hidayat, dkk, 2018). Hal ini menjadi salah satu alasan pentingnya pemberdayaan BUMDesa. Pemberdayaan terhadap BUMDesa telah banyak dilakukan pada kegiatan pengabdian masyarakat seperti pengelolaan keuangan BUMDesa (Sugiyanto, 2020) dan dari sisi pariwisata (Rozaki dan Rohaya, 2019).

Berdasarkan hasil analisa terhadap situasi eksisting maka diketahui permasalahan prioritas mitra adalah sebagai berikut:

1. Pengemasan produk mitra masih menggunakan kemasan botol plastik dan tidak disertai labeling kemasan. Hal ini dikarenakan keterbatasan pengetahuan mitra dalam mendesain label untuk kemasan.

2. Belum adanya label kemasan dari produk botol air mineral untuk memudahkan konsumen mengetahui lokasi produksi.

3. Belum adanya plang nama usaha untuk memudahkan pemasaran usaha serta label kemasan produk.

4. Mitra melakukan pencatatan keuangan secara sederhana yaitu dengan buku stok dan buku kas sehingga mitra membutuhkan waktu yang cukup lama untuk membuat laporan keuangan dan laporan pertanggungjawaban ke Desa.

5. Proses pemasaran terbatas pada usaha ATV, sekitar usaha dan pemasaran langsung di lokasi produksi

\section{METODE}

Kegiatan pengabdian masyarakat ini menggunakan metode ceramah atau pemberian informasi yaitu pemberian informasi tekait materi kegiatan agar terjadinya pemahaman yang sama terhadap materi, metode Focused Group Discussion (FGD) yang merupakan teknik diskusi kelompok untuk mendapatkan gambaran dari berbagai pendapat terhadap permasalahan yang dihadapi, metode simulasi dan latihan yaitu mempraktekkan situasi nyata yang akan dihadapi (Salmiati, dkk, 2018).

Pada metode pelaksanaan menggambarkan prosedur kerja yang akan dilakukan pada kegiatan ini. Prosedur kerja dari kegiatan ini ditunjukkan oleh Gambar 2. Terdapat enam bentuk kerja utama yang dimulai dari sosialisasi kegiatan, kemudian 
peningkatan alat produksi, pembuatan desain labeling kemasan, pelatihan manajemen keuangan, pelatihan manajemen pemasaran serta evaluasi kegiatan.

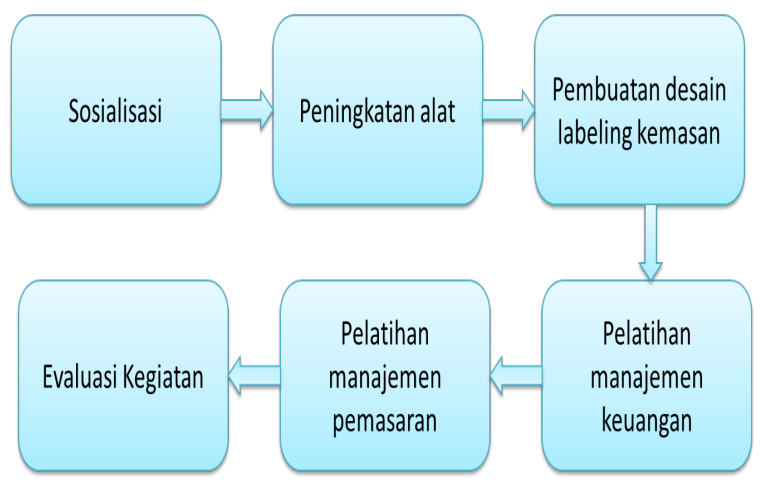

Gambar 2 Prosedur kerja kegiatan pengabdian

Berdasarkan permasalahan mitra yang menjadi prioritas maka terdapat beberapa kegiatan untuk menangani permasalahan tersebut:

1. Sosialisasi dilaksanakan dengan menghadirkan peserta dari mitra dan tim pelaksana. Pada tahap sosialisasi, akan disampaikan informasi-informasi mengenai latar belakang, target, sasaran dan tujuan kegiatan. Disamping menyampaikan maksud dan tujuan, juga dilakukan pencatatan data teknis lebih lanjut serta pencatatan visualisasi dalam bentuk video dan foto. Dokumentasi ini digunakan dalam desiminasi atau pemasyarakatan hasil pelaksanaan program.

2. Pemberian alat filter air. Hal ini akan membantu dalam proses produksi.

3. Bantuan pembuatan desain label kemasan yang menarik. Kemasan akan didesain dengan menggunakan alat bantu komputer sehingga dihasilkan desain kemasan yang menarik dan eye catching serta modern. Desain label kemasan akan langsung dicetak dalam bentuk sticker dan ditempelkan pada botol kemasan produk.

4. Pelatihan sistem manajemen keuangan berupa pelatihan penggunaan aplikasi MyOB dan pelatihan sistem penjualan produk. Diharapkan agar mitra dapat mengetahui keuntungan atau kerugian serta mempermudah pembuatan laporan keuangan.

5. Pelatihan pemasaran dengan memanfaatkan media sosial yaitu facebook dan Instagram. Media sosial sudah umum digunakan sebagai alat pemasaran produk (Kurniawan, 2017). Sedangkan website efisien sebagai sarana pomosi (Adhanisa dan Fatchiya, 2017). Selain itu untuk mendukung pemasaran produk, mitra diberikan bantuan plang nama sebagai salah satu media promosi.

6. Evaluasi kegiatan pelatihan dilakukan setelah pelatihan manajemen dan pemasaran. Evaluasi kegiatan dilakukan untuk mengetahui keberhasilan kegiatan pelatihan yang dilaksanakan.

\section{HASIL DAN PEMBAHASAN}

Sosialisasi atau pengarahan kepada mitra terkait kegiatan Pengabdian kepada Masyarakat sudah dilaksanakan pada Tanggal 15 April 2020. Pada saat itu Timmemberikan dan menyajikanmateri sosialisasi secara langsung kepada mitra kegiatan. Inti dari kegiatan sosialisasi kegiatan ini guna memberikan pemahaman yang mendetail dan menyeluruh terkait latar belakang, identifikasi masalah, solusi, target, sasaran dan tujuan kegiatan ini. Selait itu dalam kegiatan tersebut Tim menyampaikan jadwal setiap kegiatan serta mempertegas peran masing-masing pihak, baik tim dan mitra.

Penyerahan alat produksi dalam hal ini adalah alat filter air dilakukan pada tanggal 23 April 2020. Alat ini digunakan untuk membantu mempercepat proses produksi air mineral BUMDesa sehingga diharapkan dapat menghasilkan produk yang lebih banyak dan meningkatkan kuantitas produksi. Kegiatan penyerahan barang diikuti dengan pemasangan peralatan pada BUMDesa, instalasi peralatan yang diberikan beserta cara menggunakannya. Pelaksanaan kegiatan ini dilakukan sebagai penunjang keberlangsungan operasional usaha.

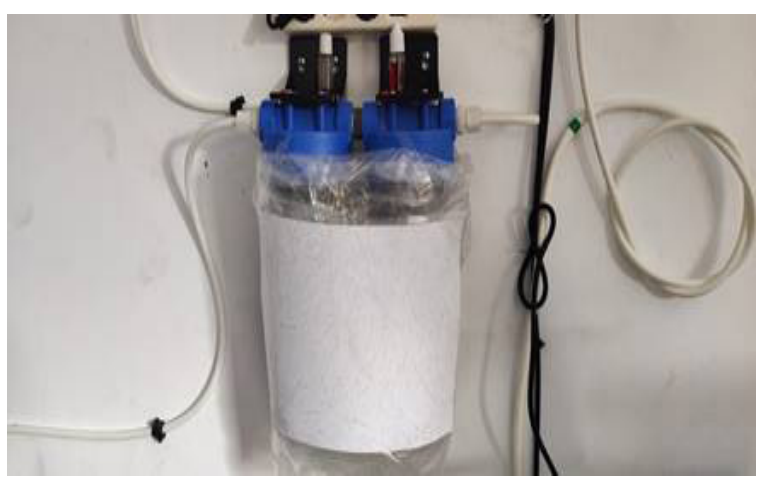

Gambar 3. Alat filter air mineral

Pembuatan Desain Labeling Kemasan Produk. Tahapan pertama yang dilakukan adalah membuat desain labeling kemasan air mineral BUMDesa. Berdasarkan hasil diskusi dengan ketua BUMDesa maka disepakati beberapa desain labeling kemasan yang akan digunakan untuk pengemasan produk yang akan dijual langsung di BUMDesa, dipasarkan di masyarakat maupun produk yang akan didistribusikan ke ATV sesuai dengan kesepakatan Kerjasama. Desain label kemasan produk air mineral ini dibuat menggunakan software Adobe Photoshop. Desain kemasan dapat dilihat pada Gambar 4.

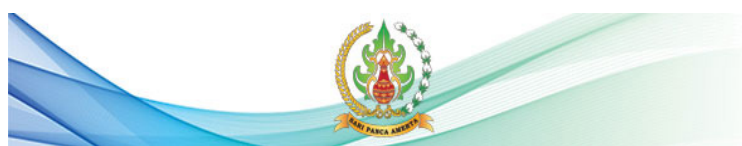

Gambar 4. Desain labeling kemasan produk air mineral 
Hasil desain ini kemudian dicetak pada stiker labeling. Pada kegiatan ini juga diberikan bantuan botol kemasan untuk produk air mineral.

Pelatihan Manajemen Keuangan. Penyerahan Manajemen Keuangan terkomputerisasi yaitu menggunakan software MyOB kepada mitra dilakukan pada tanggal 4 Mei 2020. Pelatihan ini bertujuan untuk memudahkan mitra dalam mencatat setiap transaksi keuangan sehingga nantinya dapat mengukur nilai keuntungan atau omset mitra setiap bulannya maupun menghitung pajak.

Selain itu dilakukan pelatihan sistem penjualan yang dalam hal ini adalah sistem POS (Purchase of Sale) dilakukan pada tanggal 2 Juni 2020 dan 15 Juni 2020. Sistem POS ini merupakan sistem untuk mencatat transaksi penjualan, pembelian, stok produk, laporan keuangan. Sistem ini juga telah dilengkapi dengan scan barcode dari produk. Sistem POS BUMDesa Panca Sari Amerta dapat dilihat pada Gambar 5.

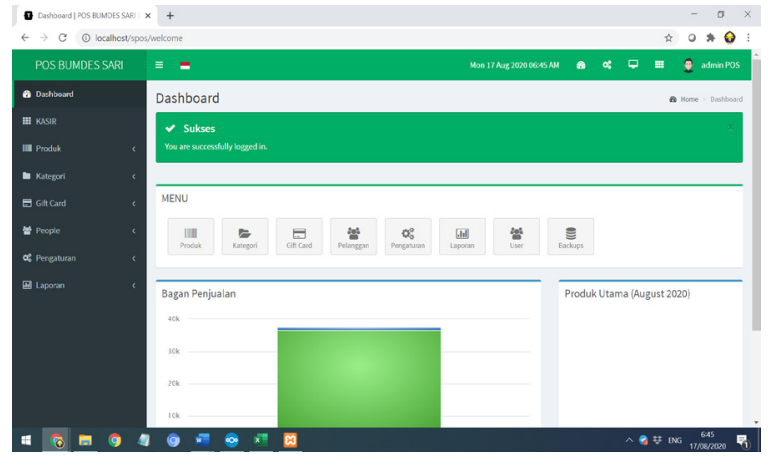

Gambar 5. Sistem POS BUMDesa Panca Sari Amerta

Pelatihan Manjemen Pemasaran. Pemasaran merupakan komponen penting dalam menjalankan usaha. Untuk memperluas pemasaran produk air mineral BUMDesa maka dilakukan pemasaran secara online. Hal ini dilakukan dengan cara memasarkan melalui media social facebook dan Instagram. Pembuatan account facebook dan instagram dilakukan oleh tim, kemudian dilanjutkan dengan pelatihan penggunaan facebook dan instagram tersebut untuk memasarkan produk. Media social BUMDesa Panca Sari Amerta dapat dilihat pada Gambar 6.

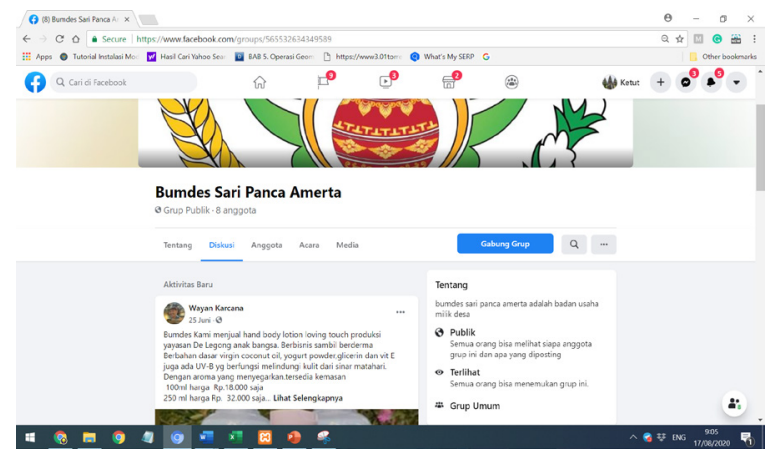

Gambar 6. Facebook BUMDesa Panca Sari Amerta
Evaluasi Kegiatan. Monitoring dan evaluasi dilakukan selama 2 tahap yaitu pada tanggal $15 \mathrm{Mei}$ 2020 dan 29 Juni 2020. Tujuan kegiatan monitoring dan evaluasi adalah untuk mengetahui ketercapaian targetsetiapkegiatanyang direncanakan. Berdasarkan hasil evaluasi, untuk kegiatan pengemasan, pemasaran dan manajemen keuangan tercapai. Sedangkan untuk target peningkatan pendapatan mitra sebanyak 50\% tidak tercapai dikarenakan adanya pandemic COVID-19 yang berdampak pada ditutupnya objek wisata termasuk ATV sehingga tidak adanya pesanan air mineral dari ATV.

\section{SIMPULAN}

Berdasarkan kegiatan yang telah dilakukan sampai saat ini maka diperoleh beberapa kesimpulan, yaitu: Bahwa kegiatan yang telah dilakukan sampai saat ini oleh Tim Pengabdian bersama-sama dengan mitra antara lain: kegiatan sosialisasi, pemberian alat bantu produksi, pembuatan dan pelatihan labeling kemasan, pelatihan manajemen keuangan, pelatihan sistem penjualan, monitoring dan evaluasi kegiatan serta penyelesaian pembuatan laporan akhir kegiatan; Bahwa bantuan alat dan sistem untuk pengelolaan BUMDesa saat membantu untuk kemajuan usaha BUMDesa; Bahwa mitra menyatakan sangat tertarik (antusias) dan terbantu karena telah mendapatkan bantuan alat maupun pengetahuan terkait keuangan dan pemasaran; Berdasarkan hasil evaluasi, untuk kegiatan pengemasan, pemasaran dan manajemen keuangan tercapai. Sedangkan untuk target peningkatan pendapatan mitra sebanyak 50\% tidak tercapai dikarenakan adanya pandemic COVID-19 yang berdampak pada ditutupnya objek wisata termasuk ATV sehingga tidak adanya pesanan air mineral dari ATV.

\section{UCAPAN TERIMAKASIH}

Terima kasih kepada Direktorat Riset dan Pengabdian Masyarakat, Direktorat Jenderal Penguatan Riset dan Pengembangan Kementerian Riset Teknologi dan Pendidikan Tinggi Republik Indonesia dan Politeknik Negeri Bali yang telah memberikan kesempatan kepada kami untuk mendapatkan bantuan pendanaan kegiatan Pengabdian kepada Masyarakat ini.

\section{DAFTAR PUSTAKA}

$$
\begin{aligned}
& \text { Adhanisa, C.M., Fatchiya, A. (2017). } \\
& \text { Website Dan Instagram Sebagai } \\
& \text { Sarana Promosi Kawasan Wisata Berbasis } \\
& \text { Masyarakat, Jurnal Sains Komunikasi dan } \\
& \text { Pengembangan Masyarakat (JSKPM), 1(4), } \\
& \text { 451-466 }
\end{aligned}
$$


Hidayat, A.T., Pujiati, L., Hidyati, N., Hendrawan, S.A., Suprapto, S., Nurali. (2018). Pendampingan Penyusunan Laporan Keuangan Pada Badan Usaha Milik Desa (Bumdes) Lestari Desa Bandung Kecamatan Diwek Jombang, COMVICE, 2(1), 16-20.

Kurniawan, P. (2017). Pemanfaatan Media Sosial Instagram Sebagai Komunikasi Pemasaran Modern Pada Batik Burneh, Kompetensi, 11(2), 217-225.

Mulyani, S., Suharman, H., Winarningsih,S., Sukmadilaga, C. (2018). Peran Anggaran Partisipatif, Good Village Governance Dalam Meningkatkan Pembangunan Desa, Dharmakarya: Jurnal Aplikasi Ipteks untuk Masyarakat, 7(3), 203-208.

Rozaki, A., Rohaya, S. (2019). Memberdayakan Desa Melalui Pariwisata Berbasis BUMDES: Studi Interkoneksi BUMDES Melalui Integrated Information System di Kabupaten Gunungkidul Yogyakarta. ENGAGEMENT, 3(1), 1-20.
Salmiati., Hasbahuddin., Bakhtiar. (2018). Pelatihan Konselor Sebaya Sebagai Strategi Pemecahan Masalah Siswa, MATAPPA: Jurnal Pengabdian Kepada Masyarakat, 1(1), 36-41.

Suprapto, P.A., Sarja, N.L.A.K., Suastika, I.N., Wongbuangam, B. (2019). Developing Rural Community Economies Through VillageOwned Enterprises in the Province of Bali, 2nd International Conference on Applied Science and Technology 2019 - Social Sciences Track, 398-404.

Undang-Undang Republik Indonesia Nomor 6 Tahun 2014 tentang Desa.

Zulkarnaen, R.M. (2016). Pengembangan Potensi Ekonomi Desa Melalui Badan Usaha Milik Desa (Bumdes) Pondok Salam Kabupaten Purwakarta, Dharmakarya: Jurnal Aplikasi Ipteks untuk Masyarakat, 5(1), 1-4. 